\title{
Los centros de detención y/o tortura en Chile. Su desaparición como destino*
}

\author{
The detention and / or torture centers in Chile. \\ His disappearance as a destination
}

José Santos Herceg**

\begin{abstract}
Resumen: El presente escrito tiene como finalidad aproximarse a los Centros de Detención y/o Tortura de la Dictadura Militar en Chile desde la perspectiva de su desaparición. El objetivo será distinguir los diferentes modos de desaparición que se organizan en tres grupos — destrucción, transformación y ocultamiento- - Se buscará poner de manifiesto que ellos coinciden con los tres tipos de desaparición diferentes: ontológica (ser), sensorial (ver) y epistemológica (saber).
\end{abstract}

Palabras clave: Centro de Detención y/o Tortura, Desaparición, Destrucción, Transformación, Ocultamiento

\begin{abstract}
This paper seeks to approach to the Chilean Detention and / or Torture Centers from the perspective of his disappearance. The objective will be to distinguish the different modes of disappearance that are organized into three groups - destruction, transformation and concealment-. It will seek to show that they are in line with the three different types of disappearance: ontological (being), sensory (see) and epistemological (know)
\end{abstract}

Keywords: Detention and/or Torture Centers, Disappearance, Destruction, Transformation, Concealment

\footnotetext{
* Este trabajo forma parte de la investigación titulada "Campos prisioneros en Chile. Reconfiguración de los lugares y las subjetividades", (FONDECYT No 1140200)

Chileno, Dr. en filosofía, académico investigador de la Universidad de Santiago de Chile, jose.santos@usach.cl
} 
Durante la Dictadura habrían existido más de 1.168 Centros de Detención a lo largo de Chile. De ellos, un número importante eran inicialmente casas particulares o casas de fundos, otras eran clínicas o edificios públicos y civiles como centros deportivos, universidades, liceos y colegios, hospitales, estaciones de bomberos, estaciones de trenes y edificios de la administración pública. Junto con ellos hay también instalaciones de uniformados que se vuelven centros de detención como unidades militares, unidades de Policía de Investigaciones, unidades de Carabineros. Incluso algunos barcos, salitreras o pueblos enteros que se convirtieron en Centros de Detención y Tortura. Finalmente podría mencionarse el caso de las cárceles, que generadas para albergar delincuentes, son utilizadas para encerrar a prisioneros políticos.

Si hay algo que de inmediato llama la atención cuando se analiza el listado de los Centro de Detención y/o Tortura que hubo en Chile durante la Dictadura Militar, es que prácticamente ninguno de ellos fue creado explícitamente para estos propósitos; lo que se observa es que casi en la totalidad de los casos de trata de una "reconfiguración" de lugares ya existentes: lugares que nacieron con otra finalidad, que son - en algunos casosrefaccionados o habilitados y que son transformados en lugares de reclusión, de interrogación, de tortura, etc ${ }^{1}$. Lugares que, por lo tanto, una vez que dejan de utilizarse como Centro de Detención y Tortura tienden a desaparecer en tanto que tales con la misma rapidez y eficiencia con que surgieron.

Silva y Rojas constatan acertadamente que hay "piezas de la ciudad artefacto" que desaparecen y que están ligadas a una memoria traumática del dolor (2004). Los Centros de Detención y/o Tortura utilizados por la Dictadura Militar son, para ellas, justamente este tipo de lugares que se encuentran "desaparecidos". Estas autoras distinguen una serie de "operadores": acciones mediante las cuales un lugar desaparece. Hablan de lugares demolidos, simulados, desconocidos, aislados, apropiados y ocultos. Estas acciones aciertan en describir procesos de desaparición, sin embargo, están lejos de agotar el fenómeno. A este listado, habría que agregar una serie de otras acciones que también tiene como resultado la desaparición. Existen así, por ejemplo, lugares que son abandonados, deshabitados, descuidados, transformados, reconstruidos, retro-convertidos, normalizados, negados, desconocidos, olvidados, etc.

Por otra parte, hay que hacer notar que aunque todos estas acciones tienen en común el hecho de que provocan la desaparición de los Centros, no tienen todos en realidad el mismo efecto. Estas acciones provocan diferentes tipos de desapariciones, que en algunas oportunidades se combinan y en otras no. Distinguimos, entonces, una desaparición ontológica, otra sensorial y una epistemológica. La del primer tipo es la desaparición que se provoca mediante los operadores, como el de la destrucción, el del desmantelamiento, el del abandono, o en algunos casos, el de la transformación, pues con estas acciones se consigue hacer desaparecer físicamente un inmueble. La desaparición sensorial por su parte, alude a

\footnotetext{
${ }^{1}$ Sobre este tema he escrito un artículo de pronta aparición titulado "La reconfiguración como el modo de llegar a ser. Surgimiento de los Centros de Detención y/o Tortura en el Chile dictatorial".
} 
aquella que implica salir del ámbito de percepción, ya no se la ve. Es evidente que este tipo de desaparición siempre se da cuando concurre una desaparición ontológica: destruido el inmueble, ya no se le percibe. Es posible, sin embargo, que la desaparición sensorial se de con independencia de la ontológica, como en el caso de que un lugar sea simulado, esté oculto, disfrazado, aislado, enajenado, etc. En estos casos, los lugares existen concretamente, pero no se les percibe más como Centros de Detención y/o Tortura. Están desparecidos porque son invisibles.

La desaparición epistemológica, en tercer término, es, aunque parezca extraño decirlo, la más radical de todas, pues cierra el círculo de la desaparición. Ella alude al hecho de que un inmueble sale del ámbito del saber: no se sabe que existe, ni siquiera se tiene noticia de que alguna vez existió. Lo habitual sería pensar que a una desaparición ontológica le siga una sensorial que acarree — a la larga - una epistemológica. Primero se destruye un lugar, por lo que ya no se le percibe y finalmente, se olvida que existió alguna vez. Esto es, sin duda, un objetivo expresamente perseguido por la Dictadura. Es posible, sin embargo, que se den alternativas diferentes. Una de ellas es que sin concurrir una desaparición ontológica y dándose solo una desaparición sensorial, a la larga un lugar termine por desparecer de ámbito del saber. También es posible, por el contrario que habiendo una desaparición ontológica y sensorial, sin embargo, no se corrobore una epistemológica. Hay, sin embargo desapariciones epistemológicas que se dan sin que se destruya o de desmantele el inmueble.

Es un hecho que la gran mayoría de estos Centros de Detención y/o Tortura parecen haber desaparecido en el Chile de hoy: ya no están, ya no se les ve y/o no se sabe de ellos. En la práctica, excepto algunas excepciones, simplemente han dejado de existir. La desaparición parece ser el destino inevitable de estos lugares y solo una acción concreta, concertada, sistemática y dirigida podría evitar en parte que ello ocurra. Como sea, cualquier acción posible en este sentido exige detenerse en un análisis de los grados y modos de desaparición. Para fines expositivos agruparemos los modos de desaparición en tres grupos — destrucción, transformación y ocultamiento- los que coinciden en general, con los tres tipos de desaparición —ontológica (ser), sensorial (ver) y epistemológica (saber) - entendiendo que ellos son transversales.

\section{A. Destrucción (SER)}

El modo más evidente en que algo desaparece es en tanto que dejar de ser. La desaparición es, en un primer sentido, ontológica, pero, por ello mismo, es también sensorial, es decir, alude al pasar del ser al no-ser con la consecuencia de "dejar de ver". En estos casos, algo sale de la vista como consecuencia del hecho de que ha dejado de existir. La desaparición aquí tiene algo de definitiva e irreversible. Un número importante de Centros de Detención y/o Tortura fueron destruidos. Dicha destrucción se llevó a cabo por 
diferentes medios: algunos activos y otros pasivos. El desmantelar, el demoler, son acciones, mientras que el abandonar es una omisión.

\section{Desmantelar / demoler}

Hacer desaparecer mediante la destrucción de todo vestigio, de las pruebas positivas de existencia fue una estrategia transversal utilizada por la Dictadura en Chile. De allí la desaparición de los cuerpos que fueron torturados hasta morir, pero también, la desaparición de los lugares en que se privó de libertad y se torturó. La demolición ha sido sistematizada con razón por Silva y Rojas como una de las estrategias principales destinadas a borrar del espacio público los lugares vinculados a las violaciones de derechos humanos (2004). De lo que se habla aquí es de que los lugares son reducidos a escombros, transformados en sitios baldíos. Como bien ha hecho ver Lawner, hablando de la destrucción del COMPINGIN en Dawson, se trata de un "...comportamiento que la Dictadura repitió más adelante con otros centros de detención, reconocidos o clandestinos, a fin de borrar toda huella de sus atrocidades" (Lawner, 2004:74). Ejemplifica con Ritoque y Puchuncaví, señalando que "fueron (...) desmantelados hasta sus cimientos una vez que cesaron de emplearse como centros de reclusión" (74-75).

Joui relata en su testimonio de qué manera a partir del 15 de abril de 1974 los mismos presos fueron usados para desmantelar el Campamento de Puchuncaví, puesto que habría de funcionar en otro lugar (Joui, 1994: 163ss). Este campamento pertenecía originalmente a la Junta Nacional de Auxilio Escolar y Becas y la Armada Nacional no se la devolvió nunca. En lugar de ello, como cuenta Joui, se "[h]izo desaparecer las ocho cabañas para no dejar huellas de que en Puchuncaví hubo un Campo de Detenidos” (1994:163). Años más tarde - 1987 - Durán, quien había estado detenido allí, viaja a visitar el lugar y no encuentra nada. Un lugareño le cuenta que “...lo destruyeron. Hace casi un año, los militares vinieron y lo destruyeron. Dejaron algunos de los paneles en un sitio vacío, dos cuadras más allá" (Durán, 2003:155). Una experiencia parecida es la de Ahumada, quien regresa al Cerro Chena el 2001, como testigo en el marco de una investigación judicial. Mira desde una loma hacia abajo y solo ve "...una plataforma rectangular de cemento que fue trabajada para que pareciera de baldosas. (...) Son 10 a 15 metros de largo por algo más de 2 metros de ancho está en el sector que mira hacía el cerro. Es lo único que dejaron de la casa de torturas en la que nos tuvieron encerrados $\mathrm{Y}$ por la que pasaron centenares de compatriotas" (Ahumada, 2011:158-159).

Las demoliciones y destrucciones en general, no se hacen esperar, se llevan a cabo tan pronto se abandona un lugar. Los últimos militares que quedaban en el Cuartel Terranova quemaron todo antes de abandonarlo. Un caso extremo es el que relata Lawner. Cuenta el arquitecto que "No han transcurrido cuatro horas desde que abandonamos la COMPINGIN, cuando al retornar, nos sorprende un panorama insólito: el campo ha sido 
arrasado" (Lawner, 2004: 74). En efecto, se trataba de una construcción liviana, hecha con paneles fácilmente desmontables y fueron desarmados, según Lawner, "igual que carpas" (74). Los prisioneros que regresaron se encontraron con que "Una gran mancha de tierra amarillenta cubre ahora el claro donde se levantaban las construcciones. Es un oasis de muerte, contrastando con el intenso verde del entorno" (74).

El tipo de destrucción al que se recurre es generalmente, total y definitiva. El objetivo fue, en todos los casos, que no quedara nada en pie. En 2003 un grupo de exprisioneros retornó a Dawson. Lawner, nuevamente, relata la llegada a lo que fue el Campo de Río Chico: "Pronto, al dar una curva, asoma la inconfundible silueta del acantilado norte que flanqueaba el campo. Hemos llegado. Desde la ventanilla del bus, se observa que no hay rastro alguno de las instalaciones donde estuvimos confinados por tanto tiempo" (2004: 153). La destrucción es completa y absoluta, literalmente ha sido borrado el mapa. Este arquitecto incorpora luego la siguiente observación de corte profesional: "Por mi oficio, he conocido innumerables demoliciones. Pero ¿cómo hicieron ésta? Observo el terreno atentamente y no advierto una sola hebra de alambre, ni siquiera un clavo. Es como si una gigantesca aspiradora hubiera succionado el mas minúsculo resto de las construcciones existentes" (153). Compara el lugar con una mesa de billar y se pregunta nuevamente “¿Cómo pudieron arrasar con todo?" (153), concluyendo finalmente que "el demoledor de Río Chico resultó tan eficaz como los que hicieron desaparecer los cuerpos de miles de nuestros compatriotas" (153).

Es relativamente claro para cualquier observador que se trata de la misma práctica utilizada por los Nazis para borrar las huellas de los Kozentrationslager, adoptada luego por la Dictadura chilena con la misma finalidad ${ }^{2}$. Luego de las demoliciones, los terrenos tienen diferentes destinos. Algunos terrenos son utilizados nuevamente, levantando allí nuevas construcciones, como se verá más adelante. Es el caso de la Clínica London, por ejemplo, en cuyos terrenos se levanta ahora un INACAP. En otros casos, siguiendo el ejemplo Nazi, a la destrucción o desmantelamiento de un lugar le sigue el abandono. Lo que fue el Campo de Prisioneros de Rio Chico en Dawson es simplemente un peladero. Lo mismo ocurre con la casa de tortura en Cerro Chena: sólo queda la loza. El abandono, sin embargo, también se da aunque el inmueble no sea destruido, aparece así otro modo de desaparición.

\section{Abandonar}

La destrucción no tiene lugar solo activamente, pues el abandono es también una forma de conseguir el mismo objetivo. Dejar a su suerte un lugar para que el seguro paso del tiempo haga el trabajo de destruirlo lentamente, hasta que no quede nada. El resultado, a

\footnotetext{
${ }^{2}$ En efecto, la hipótesis más recurrente sobre esta acción es que, en términos de Lawner, "Los fascistas criollos aprendieron las lecciones dictadas por el régimen nazi en los últimos días de la Segunda Guerra Mundial, al hacer desaparecer las huellas del holocausto desencadenado en Europa a medida que se iban retirando de los territorios ocupados" (2004:75).
} 
la larga, es el mismo: una desaparición ontológica y sensorial que con el tiempo, se vuelve epistemológica. El caso de los Konzentrationslager Nazi es paradigmático, pues aquellos que no se han preservado simplemente fueron tragados por el tiempo: el clima los fue carcomiendo y la vegetación los cubrió al pasar los años, al punto de que, en algunos casos, ni siquiera es posible saber con certeza dónde estaban. En Chile la situación de abandono de algunos - de una importante mayoría - de ex Centros es análoga. De allí el artículo publicado en La Nación el 16 de mayo de 2008, bajo el elocuente título de "Centro de tortura en completo abandono". El abandono se puede dar en diferentes modalidades y distintos grados. Dos de ellas son el deshabitar y el descuidar.

\section{- Deshabitar}

Hay lugares que luego de haber servido para la detención y la tortura, simplemente son deshabitados y dejados a su suerte. Esta situación es más esperable y sin duda más habitual en aquellos que se encuentran fuera de las ciudades, en parajes remotos. El caso paradigmático del abandono es en el que está Chacabuco, en palabras de Chavado, “...una de las llamadas ciudades fantasmas del salitre (...) hoy solo "habitadas" por el polvo y el viento del desierto" (2005:6). En Chacabuco existió por muchos años tan solo un único habitante: Roberto Zaldívar, un ex prisionero que con la vuelta de la democracia decidió instalarse allí. Montó un improvisado museo y ofrecía guías e información para los esporádicos visitantes. Llevó a cabo su autoimpuesta labor, hasta que su salud le falló, mudándose luego a Antofagasta donde murió el 16 de abril del 2009. Desde entonces el abandono es definitivo y radical, con la clara consecuencia de que el tiempo y la erosión terminarán por hacerlo desaparecer.

El abandono por des-habitación, sin embargo, no se da solamente fuera de las ciudades, en lugares remotos o descampados, sino que también al interior de los centros urbanos mismos. El llamado "Palacio de las Sonrisas", una casona en medio de Punta Arenas, en la Avenida Colón, utilizada como centro de tortura y administrativo de la DINA, permanece, desde que fue desocupado en 1976, abandonado. Cuenta Tomás Valladares: "Aún recuerdo mis paseos por el centro de la ciudad de Punta Arenas alrededor de 1995 hasta mi adolescencia pasado el 2000. Tengo grabado en mi memoria siempre encontrarme con una casa muy deteriorada, puesto que estaba abandonada, en la Av. Colón, con una frase escrita en el frontis de la construcción: AQUÍ SE TORTURÓ. Hasta el día de hoy ese recinto se encuentra intacto y se puede leer el mismo mensaje en su muro, nada más" (2014). La casa habría sido construida para servir de Hospital Naval, luego fue utilizado por la DINA. Hoy, aún en manos de los navales, sin uso y destruyéndose poco a poco espera un mejor destino. Las agrupaciones de Derechos Humanos Salvador Allende y Orlando Letelier, junto a Carlos González, presentaron un proyecto al intendente de la región, Jaime Jelinic, con el objeto de convertir el edificio en un museo dedicado a las víctimas de 
Magallanes. Según se señala en el proyecto, el inmueble "en la actualidad presenta un evidente estado de abandono...".

\section{- Descuidar}

Hay lugares que pese a que siguen estando habitados, a que aunque aún circulan personas en su interior, el abandono y el deterioro se hacen evidentes, la razón principal suele ser que simplemente no hay fondos para sostenerlos, mantenerlos y menos aún operacionalizarlos de otra forma - como sitios de memoria, de conciencia o centros culturales, etc. La consecuencia de esta desatención y descuido es a la larga, una desaparición sensorial y epistemológica que podría terminar siendo ontológica. Estos lugares no se ven, nadie - o al menos muy pocos - saben que se trata de ex Centros de Detención y Tortura. Las personas pasan por su puerta, ignorando su historia. La erosión propia del paso del tiempo se encarga de ir destruyéndolos hasta que, en el peor de los casos, terminan completamente en el suelo. El mayor de los descuidos, según acusan los involucrados, es el del Estado. El trabajo con los lugares ha quedado entregado a manos de particulares, corporaciones, agrupaciones de familiares, colectivos, etcétera. Romina Ampuero se pregunta expresamente “¿Dónde está el Estado en este trabajo?, ¿cuál es el apoyo a estas iniciativas de los organismos de Derechos Humanos?, ¿dónde está la justicia? No existe; hay atisbos de cooperación y guiños que celebran a estas organizaciones, pero que finalmente, en términos prácticos y reales, solo quedan en eso" (2013).

Los lugares que fueron usados como Centros de Detención y/o Tortura están salvo un par de excepciones - descuidados. Basta ingresar al inmueble de la casona que fuera conocida como Clínica Santa Lucía para notar el paso inexorable del tiempo con su inevitable carga de deterioro. La casa, que fue sede del MAPU y luego centro de tortura y "clínica" de la DINA, está hoy en manos de particulares, cuyas vidas estuvieron vinculas al lugar y que sostienen la casa para que no se destruya. Romina Ampuero comenta que lo poco que se logra hacer allí — visitas, historia, preservación, etc. — se "...financia con plata de nuestros bolsillos" (2013). Recursos privados y siempre insuficientes que no consiguen detener del todo el deterioro.

En un sentido cercano, las impresiones de Guadalupe Santa Cruz sobre su viaje a Pisagua dan cuenta del descuido y abandono en que se encuentra el pueblo. "En su acceso por tierra, desde la altura de los cerros, Pisagua aparece como irrisoria materialización de un nombre: como ruina insignificante, pueblo fantasma..." (Santa Cruz, 2006:107). La autora lo tilda, sin problema, de "pueblo fantasma" - aunque aún viven allí un centenar de personas - y luego prosigue con su descripción, señalado que “...semeja el decorado en desuso de una película que ha sido abandonada a su suerte. Parece escenario de una obra atemporal, a punto de caer al mar, de ser recubierta por la arena" (106.). Santa Cruz lleva a cabo un ejercicio topológico de Pisagua, según ella misma cuenta. El resultado de su 
trabajo es una descripción en la que aparecen insistentemente descriptores como precario, carcomido, oxidado, viejo, pero sobre todo, abandonado.

\section{B. Transformación (VER)}

Hay, como ya se ha observado, desapariciones que no implican necesariamente la extinción física, aunque desaparecen de la vista, salen del ser percibidos. La desaparición en estos casos alude al hecho de que estos lugares desaparecen en tanto que Centros de Detención y/o Tortura, pues ha mediado una transformación. Evidentemente, estas transformaciones son, en realidad, desapariciones: los Centros de Detención y/o Tortura dejan de existir concreta y físicamente, su sitio, su espacio físico es ocupado por otro lugar. Lugares de diferentes tipos, de distintas facturas que se instalan "sobre" el que fuera un espacio para encerrar, para interrogar, para castigar, etc. Guadalupe Santa Cruz propone al respecto el verbo "superponer" o tal vez "sobreponer" (Cf.: 2006:111). En ocasiones se conservan las estructuras físicas - muros, pisos, puertas, etc.- - pero ahora se trata de otro lugar. En estos casos se puede hablar, primero, de una conversión en cuanto a su finalidad que, en algunas oportunidades va acompañado de algún tipo de adaptación. Por otro lado, en ocasiones este cambio de finalidad alude a la intención de regresar el inmueble a su sentido original, en cuyo caso se trataría de una "retroconversión". En otras oportunidades, no se conserva nada, por lo tanto, sería necesario referirse directamente a una construcción o eventualmente una reconstrucción.

\section{Convertir}

Hay inmuebles que habiendo sido utilizados como Centros de Detención y/o Tortura, se transforman sin que se altere significativamente su estructura o aspecto. Simplemente cambia su sentido, su propósito, su finalidad, lo que lleva aparejado, en ocasiones, algún trabajo menor de adaptación para esta nueva tarea, pero no implica una variación sustancial desde el punto de vista físico. No hay una desaparición ontológica: los lugares siguen existiendo físicamente, solo cambia un poco su aspecto, su función y su finalidad lo que altera la percepción que se tiene de ellos: ya no se les ve, se han vuelto invisibles. Los lugares que fueron utilizados como Centros de Detención y/o Tortura se convierten en otra cosa, diferente. Las conversiones, por supuesto, implican varias modalidades o niveles de desaparición.

Hay, en primer lugar, algunos que cambian su sentido, su finalidad, ya no son un Centro de Detención y Tortura, ni se ve como uno, pero ello no implica un "olvido" del hecho de que lo fueron En ellos ya no se encierra, no se tortura, pero su nueva finalidad no acarrea dejar de lado que en algún momento ese fue su objetivo. Es más, hay lugares cuya nueva finalidad incluye el mantener viva la memoria de lo que fueron. Un caso 
paradigmático es el de Londres 38. El inmueble fue recuperado por el Estado en 2007 hasta entonces estaba en manos del Instituto O’higginiano. A raíz de algunas diferencias con el Ejecutivo, tal como se cuenta en la página web de Londres 38, no es mucho lo que se puede hacer en un principio, lo que provoca daños en el inmueble ${ }^{3}$. El proyecto elaborado por la mesa de trabajo - que culmina en 2007- propone su transformación en un Sitio de Memoria y un Lugar Patrimonial. Entre sus objetivos principales está reinstaurar la identidad del lugar, territorializar la memoria de Londres 38 y evidenciar la acción de desaparición. Para ello se planifica una serie de acciones concretas, la mayoría en el sentido de preservación de patrimonio, es decir, de recuperación del inmueble, a lo que se agregan algunas intervenciones como son la "placas de memoria". El caso de Londres 38 es el de la transformación de un Centro de Detención y Tortura en un Sitio de Memoria: desaparece el Centro, pero la memoria se preserva. No es, sin duda, el único caso, ni tampoco el único en Chile ${ }^{4}$.

Hay, por el contrario, lugares que cambian su sentido, su finalidad, y ello implica el dejar de la lado el hecho de que fueron Centros de Detención y/o Tortura. En ellos ya no se encierra, ni se tortura a prisionero político, su nueva finalidad acarrea, sin embargo, dejar de lado que en algún momento ese fue su objetivo. Estamos en presencia, entonces, de una desaparición sensorial que, además, se vuelve epistemológica. Lo ocurrido con Tres y Cuatro Álamos, podría ser un buen ejemplo. Estos recintos fueron utilizados como Centro de Detención entre 1974 y 1977. El primero de ellos reconocido, el segundo clandestino. Luego de haber estado desocupado por algunos años, este inmueble pasó a ser en 1991 un COD (Centro de Orientación y Derivación) del SENAME (Servicio Nacional de Menores) llamado "El Arrayán". El lugar, al parecer no ha sufrido casi modificaciones. En 2005, un reportaje de La Nación constata que el sitio no ha cambiado nada ${ }^{5}$. En el mismo sentido, Claudia Hernández del Solar señala que "En términos de infraestructura, no mucho ha cambiado. Haciendo un paralelo entre los mapas del lugar hoy y hace 40 años atrás se cementó el terreno, se hicieron nuevas construcciones, pero las antiguas se siguieron utilizando. Solo el pabellón que fue utilizado por las mujeres prisioneras políticas ya no existe" (Hernández, 2013). Esto, no obstante, algunos cambios constatables ${ }^{6}$. No hay

\footnotetext{
3 "Durante meses el lugar permaneció desocupado sin que se adoptara ninguna decisión ni medidas de conservación del lugar, lo que provocó el derrumbe de uno de sus muros a causa de las lluvias" (http://www.londres38.cl/1937/w3-article-91128.html).

${ }^{4}$ Para el caso Argentino Cf.: Da Silva Catela, Ludmila, "Exponer lo invisible. Una etnografía sobre la transformación de Centros Clandestinos de Detención en Sitios de Memoria en Córdoba-Argentina" Medalla, Peirano, Ruiz, y Walch (Editores), Recordar para pensar-Memoria para la democracia. La elaboración del pasado reciente en el Cono Sur de América Latina, Ediciones Böll Cono Sur, Santiago de Chile, pp.44-56

5 "Ver desde afuera la parte del hogar para menores infractores donde funcionaron las casas uno, dos y tres, es una fotografía de lo que era el centro de prisioneros políticos. Los pasillos oscuros, largos y con sus puertas hacia el norte, están idénticos. El mismo espacio de distribución donde permanecían los cancerberos, hoy sirve de comedor" (“Almas en pena en Tres y Cuatro Álamos", La Nación, domingo 28 de agosto de 2005).

6 "Entre los cambios, llama enorme y terroríficamente la atención, que en la esquina nor-poniente del recinto, donde en los años de la Dictadura se realizaban las ejecuciones, se construyó una capilla, que actualmente no
} 
cambio físico, pero sí sensorial y lo que es aún más relevante, se tiende a dejar de lado, a olvidar, que alguna vez fue un Centro de Detención y/o Tortura.

Además de aquellos que se convierten en lugares o sitios de memoria o con finalidades de uso público hay otros ex Centros que se adaptan para ser utilizados con destinos privados: casas habitación, locales comerciales, oficinas, etc. En estos lugares la desaparición se vuelve definitiva. Se pasa de una desaparición sensorial a una epistemológica: luego de un tiempo los visitantes ocasionales, los transeúntes, incluso los inquilinos ya no recuerdan, o nunca supieron que en ese lugar se encarceló o se torturó. Los ejemplos de este tipo de desaparición epistemológica son muchísimos, de hecho en Chile es el mecanismo más utilizado. Casos extremos, por paradigmáticos, son las casas de la DINA que luego de ser desocupadas se transforman en jugueterías, en cafeterías, sucursales de banco, etc. La novela de Carlos Cerda titulada Una casa vacía da perfecta cuenta de esta situación. El inmueble ha sido completamente renovado y una joven pareja llega a vivir allí. La casa es una casa más, parece una casa cualquiera: ni los dueños, ni los amigos saben que había sido nada menos que la famosa Venda Sexy. El Centro clandestino de Detención y/o Tortura había sido transformado y nunca se supo de su pasado.

\section{Retroconvertir}

Cabe hacer referencia aquí, en segundo lugar, a un modo particular de transformación que propongo denominar retroconversión. A lo que se alude con esta categoría es al proceso por el cual algunos lugares, habiendo sido utilizados como Centro de Detención y/o Tortura, luego se pretende que vuelvan a tener su sentido original; recuperan su finalidad inicial. Loreto López habla, en un sentido análogo, de un proceso de normalización ${ }^{7}$. Aunque la categoría propuesta por López tiene la ventaja de apuntar a la idea de una vuelta al uso normal de un lugar, insistiría, sin embargo, en hablar preferentemente de retroconversión, pues con ello se enfatiza, contra lo propuesto por López, la idea de que este regreso al uso normal es también un proceso provocado, buscado, programado. Por otra parte, dicho proceso, también contradiciendo con ello a López, no tuvo lugar solo, ni siquiera mayoritariamente en instalaciones institucionales de propiedad del Estado, sino que en gran cantidad de recintos privados. Finalmente, la categoría de retroconversión sugiere la idea de que puede ser un proceso solo parcialmente logrado o incluso fallido, pues solo apunta a una intención.

funciona como tal, pero en cuyas mamparas están las celdas de castigo. Dicho en otras palabras, allí donde se exterminaba, hoy los jóvenes son castigados. Se replica el karma de un espacio" (Ídem).

${ }^{7}$ Señala la autora que "ya que la mayoría de los recintos y centros de detención operaron en instalaciones institucionales de propiedad del Estado, tras la finalización de la Dictadura éstas regresaron a sus funciones normales, encubriendo las labores extraordinarias a las que estuvieron destinadas durante la Dictadura a través de un proceso que podría llamarse de "normalización" (2009:8). 
El caso que parece ser el más paradigmático es el del Estadio Nacional, dada su brusca transformación de Centro de Detención y Tortura inmediatamente después del Golpe Militar y su rápido desalojo y retroconversión en Centro Deportivo unos meses más tarde, con el objetivo de que allí se pudiera jugar un partido de la Selección Chilena de fútbol contra Rusia, por la eliminatoria del Campeonato Mundial. Esta situación produce claramente desconcierto entre los detenidos. En el documental llamado Estadio Nacional (Parot, 2001) se recoge el testimonio de un futbolista en el que esto se hace evidente: en el mismo lugar jugó, fue detenido y torturado, para luego retornar, unos meses después, como espectador de un partido. De acuerdo con los testimonios, la situación del Estadio Nacional no deja a nadie indiferente, fundamentalmente por el contraste de sus transformaciones. Cabe hacer notar que en términos de desaparición, este caso es, sin duda, un experiencia fallida, pues el Estadio Nacional no sólo sigue existiendo físicamente casi sin modificación, está a la vista de todo el mundo, sino que en él se conserva tal cual, como museo, una de las escotillas, una vez al año se lleva a cabo una velatón y en el partido inaugural de la Copa América 2015 se dejó vacía toda una galería para conmemorar a los prisioneros y torturados de ese lugar. Incluso uno de los jugadores, tras la victoria, aludió expresamente al hecho de haber dado a Chile una alegría allí donde tantos habían sufrido. Es posible decir, por lo tanto, que Estadio Nacional, pese a proceso de retroconversión, en tanto que Centro de Detención y Tortura no ha desaparecido.

Como contra ejemplo, un caso paradigmático de una retroconversión aparentemente lograda podría ser el de La Esmeralda, buque insigne de la Armada que fue utilizado como Centro de Detención y Tortura, pero que posteriormente y tras un sistemático y fuerte trabajo publicitario parecer retomar su lugar como Buque Escuela, como "Dama Blanca". No puede dejar de mencionarse, sin embargo, el hecho de que todavía el año 2011 hubo una jornada de repudio en Vancouver, Canadá (6, 7 y 8 de agosto), por su visita. Diferente es el caso de los Buques: el Lebu, el Maipo y el Andalién. Fueron utilizados como lugares de detención, para trasladar detenidos, pero luego retornaron a sus funciones como buques de cargamento.

Lo más habitual es que la retroconversión opere eficientemente, esto es, que se devuelvan los inmuebles a su finalidad anterior y que al poco andar, sin que medie intervención alguna, simplemente el lugar desaparezca epistemológicamente: ya nadie sabe ni recuerda que fueron Centros de Detención y/o Tortura. La sorpresa con que reaccionan las personas al enterarse de que, por ejemplo, las dependencias de algunas universidades tuvieron estas funciones o las de algunos hospitales, incluso las de compañías de bomberos o colegios, da cuenta de lo que se viene diciendo. La tranquilidad con que circulamos por loa alrededores o incluso al interior de algunos de estos inmuebles en la ignorancia más completa, sirve para demostrar lo mismo. La retroconversión de los inmuebles provoca, en la mayor parte de los casos, una desaparición epistemológica absolutamente lograda.

Especialmente interesante, en este punto, es el caso del Centro Clandestino de Tortura conocido como la Venda Sexy. Una vez que se dejó de usar, simplemente fue 
devuelto a su dueño, puesto que la DINA lo arrendaba a un particular. Dada su clandestinidad, el inmueble no fue identificado hasta mucho tiempo después. En el intertanto, la casa retornó al mercado inmobiliario y hasta hoy es habitada por una familia. En un primer momento, mientras la casa no había sido identificada, estamos ante un caso de desaparición epistemológica completa producto de su retroconversión, sin que medie, desaparición ontológica ni sensorial. El desconcierto de los vecinos e incluso del mismo dueño de la casa al enterarse por los medios que había sido un Centro de Tortura da prueba de su desaparición. Una vez que la casa es identificada y es marcada, comienza un proceso sumamente interesante que puede describirse una acción que busca devolverle su existencia, en el sentido de hacerla reaparecer.

\section{3. (Re) Construir}

Un gesto extremo de desaparición ontológico/sensorial, como se decía, es el destruir, el desmantelar. Uno aparejado y que lo vuelve aún más definitivo, dado que podría servir para radicalizar la desaparición agregando una de orden epistemológica, es el de construir sobre los escombros o en el sitio eriazo que ha quedado. La desaparición más completa, más exitosa, se da en el caso en que sobre los restos de lo que fuera un Centro de Detención y/o Tortura se construye otra cosa, una completamente diferente, que no preserva ni lo más mínimo, ni recuerda en nada lo que fue. La clínica London, como se comentaba antes, es destruida para construir allí una sede del INACAP en la que no hay vestigio alguno de que alguna vez fue un Centro. La Cárcel Pública de Santiago ahora es, como se sabe, un Banco Santander. Lo que fuera el Cuartel Simón Bolívar es un condominio de casas lujosas en la comuna de La Reina. Juoi escribe en su testimonio: "Me senté frente a un escritorio de una pequeña oficina de la base aeronaval de El Belloto (ahora existe un gran complejo habitacional)" (Joui, 1994:13).

La desaparición ontológico/sensorial, sin embargo, podría no llevar necesariamente a una de orden epistemológico. Una nueva edificación podría contener marcas, restos, algún vestigio conservado o bien referencias expresas que evocaran lo que fue: placas conmemorativas. El caso más claro, en este sentido, son los Sitios de Memoria que fueron construidos desde cero sobre las ruinas de lo que fuera el inmueble original ya destruido. Este es el caso de la Casa Memoria José Domingo Cañas y el Parque por la paz Villa Grimaldi. Aquí la desaparición de los centros es total y casi absoluta desde el punto de vista ontológico y sensorial; sin embargo, la nueva edificación tiene como una de sus finalidades principales justamente evitar que concurra la de orden epistemológico: para que se sepa, para que no se olvide. 


\section{Ocultamiento (SABER)}

La desaparición epistemológica de un Centro de Detención y/o Tortura no exige que se le destruya, se le modifique, que se transforme su fisonomía o se cambie su finalidad, basta simplemente que salga del ámbito de saber. De hecho no es difícil pensar en casos en los que sin que haya una desaparición ni ontológica, ni sensorial, sí se de una de carácter epistemológica, pues no se sabe que un lugar fue alguna vez un Centro de Detención y/o Tortura. Lo más habitual, sin embargo, es que dada la desaparición de los dos primeros tipos, concurra la tercera para rematar su desaparición. Luego de una visita a Villa Grimaldi, un colega me comentó que pasaba por la Av. Arrieta todos los días rumbo a su trabajo, pero nunca supo que allí estaba ese lugar, ni menos que había sido un Centro de Tortura. Como en este caso, circulamos por las ciudades cotidianamente, sin saber muchas veces que una casa, un café, un banco, una universidad que vemos todos los días fue un Centro. Recuerdo la sorpresa de una alumna cuando supo que justo frente a su casa, allí donde ahora hay un INACAP, fue donde funcionó la clínica London.

Estamos aquí en presencia de un modo de desaparición mucho más sutil que una destrucción o una transformación y por lo tanto, la dificultad para percibirlo aumenta. Esto mismo provoca que se trate de un tipo de desaparición de la mayor radicalidad: si de la existencia de un ex Centro no se sabe, simplemente ya no existe. Por el contrario: un inmueble puede ser destruido, borrado del mapa, sobre él puede construirse otra cosa completamente diferente, pero si aún es sabido que existió, si permanece en el ámbito del conocimiento colectivo o al menos de algunos individuos, no desaparece del todo.

La desaparición epistemológica funciona a través del mecanismo general del ocultamiento. Un Centro de Detención y Tortura sale del ámbito del saber porque está oculto para el entendimiento, de tal modo que o bien no se sabe de él o bien en algún momento se supo, pero se ha olvidado. La ignorancia y el olvido son las herramientas que concurren haciendo posible esta desaparición de los Centros. Hoy en Chile la gran mayoría de los que fueron Centros están en esta condición: nadie - o muy pocos — saben que lo fueron y muchos de aquellos que lo supieron, ya no lo saben pues lo han olvidado con el paso del tiempo. Los mecanismos de ocultamiento apuntan justamente en esta dirección, es decir, buscan desinformar —o simplemente no informar - para que no se sepa, o bien pretenden restringir su aparición o cambiar su modo de presentación con el objeto de provocar el olvido.

Las modalidades de ocultamiento utilizadas en Chile han sido varias y se han implementado sistemáticamente, al punto de que no parece desencaminado hablar de una cierta "política de ocultamiento" que operó y opera tanto activa como pasivamente. En efecto, se trata de procedimiento aplicado primero durante la Dictadura, pero que en su gran mayoría ha seguido dándose hasta hoy. Hay tanto acciones como omisiones que conducen a la desaparición epistemológica de los lugares. Entre las del primer tipo - acciones - se puede mencionar, al menos, la prohibición, la simulación, la negación. Entre las del 
segundo orden —omisiones_- el aislamiento, el abandono y la desinformación. Todas ellas tienen como finalidad conseguir un determinado efecto: que no se sepa, que no se tenga certeza o se olvide que un determinado lugar fue un Centro de Detención y/o Tortura.

\section{Esconder}

Se ha señalado que hasta la fecha se sabe de la existencia de 1.168 Centros de Detención y/o Tortura en Chile, magnitud a la que se ha llegado luego de años de investigación. Es un número simplemente enorme que sorprende e impacta, sin embargo, es posible sostener que esta cifra no es definitiva, que estos no son todos los Centros que existieron durante la Dictadura: ellos son de los que se tienen noticia hasta ahora. La clandestinidad con la que trabajaron los organismos de inteligencia, unida a la ceguera provocada sistemáticamente a los detenidos y a la negación de colaborar tanto de los involucrados como de las instituciones a las que estaban ligados, hizo realmente difícil identificar algunos lugares de los que hoy se sabe que existen o existieron. Dichas barreras, como es bien sabido, no han sido traspasadas del todo, por lo tanto, parece razonable suponer que existieron otros Centros de Detención y/o Tortura de los que aún nada se sabe. Estamos aquí ante una desaparición absoluta de los lugares provocada sistemática y programáticamente. Los Centros permanecen escondidos hasta hoy y solo una suposición hace posible asumir que - tal vez- existieron.

\section{- Aislar}

Los agentes de la Dictadura utilizaron variadas estrategias para esconder sus Centros. Una de ellas fue, como bien han visto Silva y Rojas, el aislamiento. Los lugares permanecen al margen, fuera de los circuitos de circulación. Es por ello que la Dictadura instala Centros en parajes remotos como Chacabuco, en lugares de difícil acceso como Pisagua o que están incluso más allá de las costas, en islas como Dawson y la Isla Quiriquina, en medio de un bosque prácticamente sin acceso, como el caso de Isla Riesco o construidos al interior de un fundo en el llano Lliu Lliu, valle de Colliguay. El aislamiento se logra, también, con medidas de fuerza. En esta línea está, por ejemplo, la prohibición de ingreso, como en el caso de las dependencias de los uniformados -Escuela Militar, Academia de Guerra, etc - o la plantación de campos minados —este es el caso de Chacabuco, por ejemplo. Cuenta Zaldívar, que "Una vez que el campo fue desmantelado los militares se encargaron de minar los alrededores para amedrentar a aquellos que desearan conocerlo... La idea era que Chacabuco fuera devorado por el desierto" (Chavado, 2005:7). Es evidente en este punto, la política sistemática de aislamiento de los Centros desplegada por la Dictadura: había que manterlos más allá del margen de la vida, ocultos para que nadie los viera. 
Interesante resulta constatar que pasados ya más de quince años de terminada la Dictadura, los lugares que estaban o fueron aislados, permanecen aislados: no hay mejores accesos, en algunos casos ni siquiera existen accesos. A la llamada Isla Riesco casi no se puede llegar, lo que, de hecho, ha impedido llevar a cabo diligencias judiciales que están pendientes por estas dificultades de acceso. Las prohibiciones aún existen, no es posible visitar las dependencias de las Fuerzas Armadas en donde se encerró, torturó, exterminó. En algnos casos ni siquiera han sido levantadas las minas. En Chacabuco, por ejemplo, se comenzó recién en 2009 el trabajo de quitar las minas antipersonales y se hizo dada la existencia de una Comisión Nacional de Desminado (CNAD), que es la institución encargada de velar el cumplimiento del tratado de Ottawa, que impone la obligación en levantar el sembrado de minas, antes del año 2012.

\section{- Simular}

Los Centros fueron escondidos por la Dictadura también de otras formas, no solo aislándolos. Una de las estrategias más usadas fue la simulación, estrategia de la que Rojas y Silva también dan cuenta. Simulado es un lugar que desparece pues representa o pretende ser algo fingiendo o imitando lo que no es, es decir, está disfrazado. Los Centros clandestinos, como es evidente, simulan, se disfrazan y para ello utilizan diferentes estrategias. Un ejemplo muy paradigmático de ello es Londres 38. En este caso se habla de tres intentos de "borradura": al cambiar su número, al cambiar su destino y al tratar de rematarlo. El cambio de número de 38 a 40 es un claro ejemplo de simulación: se esconde el centro tras una nueva numeración, se le disfraza con otra dirección falsa.

El caso de Melinka es interesante también. Según informa Joui: "El Campo de detenidos de Colliguay empezó a funcionar en la primera quincena de Diciembre del 73. Para ocultar su existencia los marinos le pusieron Melinka. Melinka es el nombre de una pequeña isla, que está ubicada al Sur de Quellón” (1994:113). En algunos casos, la simulación de Centros urbanos implicaba, por ejemplo, la existencia de guardias disfrazados de cuidadores de autos que vigilaban el perímetro. Colonia Dignidad es, quizás, el mejor ejemplo de simulación: tras la cara visible de un asentamiento alemán autosustentable se escondieron las más terribles atrocidades.

Acabada la Dictadura, los lugares siguien siendo simulados, disfrazados. En este caso podría decirse, por ejemplo que lo que se ha descrito como transformaciones en muchas oportunidades operan como simulación. Mediante cambios de sentidos, de finalidad, que pueden o no ir acompañados de alteraciones físicas, un lugar pretende no ser lo que fue y así se busca, de alguna manera, limpiarlo, exorcizarlo ocultando que se trata de un ex Centro de Detención y/o Tortura. La simulación, en estos casos, opera mayoritariamente con estrategias pasivas, es decir, por omisión: simplemente no se insiste en hacer ver, en recordar, en poner de manifiesto el hecho de que el local que hoy se utiliza para vender, vivir, pasear, etc, antes fue un lugar en que se detuvo y/o se torturó a personas. 
No se instala placa alguna conmemorativa, no se informa a quienes lo frecuentan, no se denuncia, etc. Con el tiempo, ya nadie recuerda lo que ocurrió en dicho lugar.

\section{Silenciar}

Ignorancia y olvido: habitantes que no saben o no recuerdan que su casa fue un Centro de Detención y/o Tortura, jóvenes que nunca se enteraron y si lo hicieron ya no tienen presente que su colegio o su universidad fue utilizada para apresar o torturar. El silencio - los silencios - es de una de las causas más evidentes de esta falta de conocimiento y de esta pérdida de memoria. Los Centros de Detención y/o Tortura son un fenómeno rodeado, atravesado por múltiples silencios. Silencios que sirven para ocultar los lugares activamente, pues se niega su existencia, o bien pasivamente, pues de estos lugares no se habla, simplemente se calla su existencia. El silencio, como bien se sabe, no es solo una omisión, sino una acción. Una acción que, en este caso tiene como consecuencia la desaparición.

\section{- Negar}

Es bien sabido que la Dictadura negó sistemáticamente la existencia de la gran mayoría de los Centros de Detención y/o Tortura, reconociendo solo la de algunos lugares de detención como Tres Álamos, Chacabuco, Puchuncaví, la Cárcel Pública, donde los detenidos podían recibir visitas y desde donde eran liberados. Por contraposición, en su gran mayoría, la existencia de Centros de Detención se mantiene en secreto. La de aquellos en los que además, se tortura o se extermina siempre se mantuvo en secreto y mientras permanecen clandestinos, no existen más que para aquellos que los habitan: agentes y prisioneros. El secreto se vuelve, entonces un elemento central en el ocultamiento. Agnes Heller ha definido el secreto como “...la privilegización de algunos contenidos cognoscitivos, es la iniciación al conocimiento de algún saber que (...) es comunicado a personas elegidas según determinados criterios" (Heller, 1987:327). Existe un grupo restringido de sujetos que son los que pueden acceder a la información privilegiada. Entre ellos se firma una suerte de "pacto de silencio", como el que funciona hasta el día de hoy entre los participantes de la Dictadura y que ha hecho imposible avanzar en las causas de violación a los derechos humanos. Es lo que Goffman ha llamado "secretos internos" (inside screts) que son, según explica el autor, "aquellos que indican la pertenencia del individuo a un grupo y contribuyen a que el grupo se sienta separado y distinto de los individuos que no están 'en el saber'” (Goffman, 1959: 88 [2004:153]).

El secreto se guarda por el hecho de pertenecer a un grupo y con el objeto de seguir siendo parte de él, pero ese no es su único fundamento. Se guarda un secreto, también, porque siendo parte del grupo se busca preservar y proyectar determinada imagen de uno mismo y del grupo al que se pertenece. Aquellos secretos que Goffman llama "oscuros" 
(dark secrets) son los que tienen su razón de ser en el hecho de que se trata de hechos concernientes al equipo que este conoce y oculta, y que son incompatibles con la imagen de sí mismo que el equipo se esfuerza por presentar y mantener ante su auditorio" (Goffman, 1959:87 [2004:152]). Se calla, entonces, con el objetivo de que el resto, los otros, los no integrados adquieran y conserven una representación del grupo tal y como el grupo quiere proyectarse. Los militares manejan un discurso salvacionista - han salvado a Chile del caos marxista - y refundacional, que es claramente incompatible con la existencia de Centros de Detención y/o Tortura. La población no puede ni debe saber que para salvar y refundar Chile se detiene, se tortura, se asesina, se hace trabajar forzadamente, se hace desaparecer personas, etc. No se debe filtrar el secreto de la existencia de lugares que sirven a estos propósitos y menos aún que dichos lugares son cientos, que muchos están en medio de las ciudades en el centro de la cotidianidad. Ello enturbiaría, ensuciaría la imagen que se quiere proyectar.

Por otra parte, el secreto es funcional a los objetivos que se buscan alcanzar. Es el caso de los llamados "secretos estratégicos" (strategic secrets), de los que habla también Goffman. "Atañen a los propósitos y capacidades del equipo, que este oculta a su auditorio a fin de impedirle que se adapte eficazmente al estado de cosas que el equipo se propone lograr" (Goffman, 1959: 88 [2004:153]). De lo que se trata es que el grupo — de hombres de negocios o militares especialmente- quiere alcanzar ciertos objetivos y esconde información relativa al grupo — capacidades y propósitos-, que permitiría a los otros hacer que ello no se cumpla. Si la existencia de los Centros de Detención y/o Tortura se hubiera hecho pública, si se hubieran reconocido oficialmente, entonces el "enemigo interno" habría tenido la oportunidad de adaptarse eficazmente al estado de cosas. La oposición hubiera podido implementar estrategias más eficaces de resistencia, tanto a nivel nacional como internacional, logrando que los Centros no cumplieran cabalmente su función.

Por otro lado, el secreto es compartido por quienes participaron y apoyaron a la Dictadura sin ser parte del equipo; sin ser uniformados o miembros. Goffman habla aquí de "secretos depositados", pues se trata de terceras personas que conocen el secreto, pero no lo revelan; les ha sido confiado, y se ven obligados a conservarlo, dada su relación con el equipo. En este sentido hace ver Vidal que "El Informe Rettig da cuenta, por ejemplo, de que la crema de la intelectualidad de la Universidad Católica que apoyó al régimen militar supo tempranamente de las atrocidades cometidas por las Fuerzas Armadas y prefirió no intervenir decisivamente para conservar su influencia política" (Vidal, 2000:13). Se conserva entonces un secreto, pues se han obtenido ganancias directamente por los logros del equipo: dicha ganancia hace cómplices y por lo tanto, obliga a callar.

Los secretos profundos y aquellos estratégicos que también son profundos, señala expresamente Goffman, son secretos "eternos", es decir, el equipo, plantea el autor "... trata de mantener para siempre ocultos los secretos profundos" (Goffman, 1959: 88 [2004:153]). Cuando este tipo de secreto se vuelve "interno" es que los lazos entre los 
miembros se estrechan y la exigencia de mantenerlo se torna radical. Es en esta situación en la que el "pacto de silencio" se vuelve inquebrantable. Es el vínculo que obliga hasta hoy a quienes encerraron, torturaron, asesinaron y habitaron activamente los Centros de Detención y Tortura. El círculo de silencio se mantiene casi inquebrantable y se perciben tan solo algunas mínimas fisuras que aparecen después de muchos años. Aún hoy la imagen de la Dictadura Militar se preserva mediante el secreto y la negación. Es un secreto que sirvió y sirve todavía a sus objetivos.

\section{- Callar}

La existencia de los Centros de Detención y/o Tortura fue un secreto a voces. Se sabía de su existencia, aunque no haya habido ningún reconocimiento oficial de ello por parte del Estado. Otra forma de negación alude al hecho de que no se acepta, no se quiere aceptar su existencia. La información se tiene, circula, es posible que llegue a nuestros oídos, sin embargo, aún así y contraviniendo los datos, se niega su existencia. Ceguera voluntaria. Pilar Calveiro hay hecho ver acertadamente que "[e]l campo de concentración, por su cercanía física, por estar de hecho en medio de la sociedad, 'del otro lado de la pared', sólo puede existir en medio de una sociedad que elige no ver, por su propia impotencia, una sociedad 'desaparecida', tan anonadada como los secuestrados mismos" (Calveiro, 1998: 147 ).

Londres 38, Clínica Santa Lucía, Clínica London inmuebles insertados en el centro mismo de Santiago. José Domingo Cañas, La Venda Sexy, casas en barrios residenciales de la capital. Los prisioneros escuchan ruidos de vehículos, voces, campanadas, etc. Son golpeados, torturados, gritan, los torturadores los increpan, los guardias dan órdenes, la radio a todo volumen, autos extraños circulan, personas circulan... Nadie afuera ve ni oye nada: nadie quiere hacerlo. Chile calla. Un país secuestrado por los uniformados, que teme hablar. El miedo amordaza, silencia a fuerza. Las voces vienen de fuera, más allá de las fronteras, se escuchan en tribunales internacionales, en ONGs, Organizaciones de Derechos Humanos, etc. Solo algunos alzan la voz dentro del país - Vicaría de la Solidaridad, CODEPU—, muchos pagan caro su atrevimiento. Lo que prima es el silencio.

Pasa la Dictadura y el silencio permanece. Un mandato de silencio, una política del silencio, un discurso del silencio. Hay que dejar el pasado atrás, es indispensable mirar hacia adelante, se pregona. Los Centros de Detención y Tortura son destruidos, derrumbados, abandonados, convertidos, reconvertidos y por supuesto, olvidados. De ellos simplemente no se habla y se van borrando así de la existencia. Sólo algunos lugares logran permanecer en el ser gracias a las iniciativas ciudadanas y privadas. Del resto, ni una palabra. Una sociedad que elige olvidar lo que supo, que elige callar. Nuevas generaciones que no escucharon, que no saben que alguna vez hubo lugares en los que se detuvo y torturó a los chilenos, que esos lugares están allí, en el medio de la ciudad, por donde transitamos diariamente. 
Con este silencio se cierra, se sella una sistemática y concertada campaña de desaparición de los Centros de Detención y Tortura. Con los lugares desaparece la detención y la tortura, los trabajos forzados y los asesinatos. El olvido y la ignorancia se instalan. Un olvido e ignorancia deseado y buscado por la Dictadura y sus simpatizantes, uno que se va ahondando y perpetuando en democracia, ahondando el daño de las víctimas. Los "presuntos" desaparecidos, junto a las "supuestas torturas" que se llevaron a cabo en los "inexistentes" centros clandestinos de detención. Los chilenos fuimos y somos objeto de una estrategia de negación, de desprestigio de las víctimas, de ocultamiento de información, de alteración de la realidad, etc. Esto, por supuesto, durante la Dictadura, pero también hoy en día.

\section{Conclusiones}

La reversibilidad es el tema con el que quisiera terminar. Hay acciones que parecen no tener vuelta: hay desapariciones que tienden a ser definitivas. Lo destruido no se puede rehacer. Una vez desmantelado o abandonado un inmueble hasta su ruina, no es fácil su recuperación. Esto se extrema, si se construye encima, si se sobrepone algo completamente diferente. Similar es lo que se ocurre en aquellos lugares que han retornado a sus usos habituales "como si nada hubiera pasado" o que se han destinado a nuevas finalidades, dejando atrás su pasado oscuro. Ninguna de estas acciones, sin embargo, es completamente definitiva. Lo destruido se puede reconstruir, lo abandonado y deteriorado se puede recuperar y restaurar, lo que está oculto bajo otra construcción puede ser mostrado, así como es posible que aquellos lugares retroconvertidos no dejen del todo de lado su pasado.

La desapariciones ontológicas y sensoriales son profundas y devastadoras, pero no necesariamente definitivas. La verdadera irreversibilidad se da si la desaparición es de orden epistemológico. Si un lugar sale del ámbito del saber, si es olvidado, simplemente desaparece para siempre. Un lugar puede ser destruido, escondido, reconstruido, destinado a otra cosa o a la misma anterior, pero sólo desaparecerá del todo si se olvida que fue un Centro de Detención y/o Tortura. Mientras se sepa, en tanto se recuerde que allí la Dictadura destrozó la vida de miles de chilenos, ellos seguirán existiendo. La historia y la educación, los testimonios y los documentos adquieren, entonces, un lugar central en la lucha contra la desaparición de los lugares, en la lucha contra la Dictadura, en la lucha para que "nunca más". Una campaña de preservación tendría que contemplar estrategias y acciones destinadas a contrarrestar los tres tipos de desaparición, buscando evitar que los Centros dejen de ser - intentando que persistan en la existencia—, que se les deje de verque se conserven en el ser percibidos- y sobre todo, evitando que sean olvidados y por lo tanto, que permanezca siempre en el ámbito del saber. 


\section{BIBLIOGRAFÍA}

Ahumada Lillo, Manuel (2011), Testimonio: Cerro Chena, un campo de prisioneros, Leonardo Sepúlveda producciones gráficas, Santiago. Libro [Cerro Cena: testimonio, Ed. Tierra mía, Santiago de Chile]

“Almas en pena en Tres y Cuatro Álamos", La Nación, Domingo 28 de agosto de 2005.

Ampuero, Romina, (2013), "Clínica Santa Lucia 162 (1974-1976)", Rufian No15, 10 de septiembre de 2013 http://rufianrevista.org/?portfolio=clinica-santa-lucia-162-1974-1976.

Calveiro, Pilar, (1998), Poder y desaparición, Buenos Aires, Colihue.

"Centro de tortura en completo abandono", La Nación el 16 de mayo de 2008.

Chavado, Rubén, (2005), "El guardián de la memoria”, Revista Patrimonio Cultura, No37, año X, pp.6-8.

Durán, Claudio, (2003), Autobiografía de un exjugador de ajedrez, LOM, 2003.

Goffman, Irving, (2004), La presentación de la persona en la vida cotidiana, Amorrortu Editores, Buenos Aires/Madrid (The Presentation of Self in Everyday Life, 1959).

Heller, Agnes, (1987), Sociología de la vida cotidiana, Península, Barcelona.

Hernández, Claudia, (2013), “¿Condiciones para la perversión? La cárcel como lugar de castigo, trauma y desresponsabildiad. IV parte", La Pala. http://www.lapala.cl/2013/condiciones-parala-perversion-la-carcel-como-lugar-de-castigo-trauma-y-desresponsabilizacion-iv-parte\#_ftn1

Joui Joui, Sadi Renato (1994 y 2003): Chacabuco y otros lugares de detención. SantiagoValparaíso, autoedición.

Lawner, Miguel, (2004), Retorno a Dawson, LOM.

López, Loreto, (2009), "De los Centros de Detención a lugares de Memoria del terrorismo de Estado", Revista Praxis, Universidad Diego Portales, año 11, nº 15, Chile, 2009.

Parot, Carmen Luz, (2001), Estadio Nacional

Santa Cruz, Guadalupe, "Capitales del Olvido", en Richard, N., Políticas y Estéticas de la Memoria (1990-2010), Editorial Cuarto Propio, Santiago, 2006, pp.104-112.

"Santa Lucia 162, clínica de la DINA", Punto Final, Edición 798, 24 de enero de 2014.

Silva, Macarena y Rojas, Fernanda, (2004), Sufrimiento y desapariciones. El manejo urbanoarquitectónico de la memoria urbana traumatizada, Seminario de investigación, Departamento de Urbanismo, Facultad de Arquitectura y Urbanismo, Universidad de Chile. , (2011), "El manejo urbano-arquitectónico de la memoria urbana traumatizada", Ciudad y Memorias. Desarrollo de Sitios de Conciencia en el Chile actual, Corporación Parque por la paz Villa Grimaldi, pp. 78-84.

Valladares, Tomás, (2014). "Magallanes en Dictadura. Un trauma social", Trabajo final de seminario, Magister en Arte, Pensamiento y Cultura latinoamericanos, Instituto de Estudios Avanzados, Universidad de Santiago de Chile.

Vidal, Hernán, Chile, (2000), poética de la tortura política, Mosquito Editores. 